\title{
Properties of 130 kDa Subunit of Monkey Aldehyde Oxidase
}

\author{
Tasuku Asakawa, ${ }^{a}$ Kunio Itoh, ${ }^{a}$ Mayuko Adachi, ${ }^{a}$ Kouichi Hoshino, ${ }^{a}$ Nobuaki Watanabe, ${ }^{b}$ and \\ Yorihisa TANAKA*,a \\ ${ }^{a}$ Department of Drug Metabolism and Pharmacokinetics, Tohoku Pharmaceutical University; 4-4-1 Komatsushima, \\ Aoba-ku, Sendai 981-8558, Japan: and ${ }^{b}$ Drug Metabolism and Pharmacokinetics Research Laboratories, Daiichi-Sankyo \\ Co., Ltd.; 1-2-58 Hiromachi, Shinagawa-ku, Tokyo 140-8710, Japan.
}

Received September 17, 2007; accepted December 10, 2007; published online December 17, 2007

We previously demonstrated the existence of a minor $130 \mathrm{kDa}$ subunit in the sodium dodecyl sulfate-polyacrylamide gel electrophoresis (SDS-PAGE)/Western blot analysis of monkey liver cytosol and expressed monkey aldehyde oxidase (AO) in Escherichia coli. In contrast, the $130 \mathrm{kDa}$ subunit was not observed in rat AO. In the current study, the properties of the $130 \mathrm{kDa}$ subunit were investigated from the viewpoint of species differences in the presence of the subunit and AO activity. Monkey AO with His-tag at the $\mathrm{N}$ - and C-terminus were expressed, and were immunoanalyzed with anti-AO and anti-His-tag antisera. The results revealed that the minor $130 \mathrm{kDa}$ subunit was produced by cleavage at the $\mathrm{N}$-terminal side of the $150 \mathrm{kDa}$ subunit. The cleavage point was shown to be located between $188 \mathrm{Leu}$ and 189 Pro of $150 \mathrm{kDa} \mathrm{AO}$ subunit by the Edman degradation method. The two amino acids related to the cleavage are contained in the linkage between the $2 \mathrm{Fe}-2 \mathrm{~S}$ and FAD domains in $\mathrm{AO}$ of human and monkey, but not in $\mathrm{AO}$ of rat and mouse. As a fact, the $130 \mathrm{kDa}$ subunit was observed in $\mathrm{AO}$ of human and monkey, but not in $\mathrm{AO}$ of rat and mouse, suggesting the two amino acids might be one reason of a species difference in the formation of the $130 \mathrm{kDa}$ subunit. However, the existence of the $130 \mathrm{kDa}$ subunit is not associated with the species differences in $\mathrm{AO}$ activity, because the cleavage results in the loss of $2 \mathrm{Fe}-2 \mathrm{~S}$ cluster domain essential for exertion of $\mathrm{AO}$ activity.

Key words aldehyde oxidase; subunit; Escherichia coli expression; monkey

Aldehyde oxidase (AO, EC 1.2.3.1) is a major member of the molybdenum hydroxylase family along with xanthine oxidase. Both enzymes consist of a homodimer with a subunit molecular mass of about $150 \mathrm{kDa}$. Each subunit contains a molybdopterin cofactor, a flavin-adenine dinucleotide (FAD), and two different $2 \mathrm{Fe}-2 \mathrm{~S}$ redox centers that are essential for catalytic activity. AO catalyzes the oxidation of a wide range of endogenous and exogenous aldehydes and $\mathrm{N}$-heterocyclic aromatic compounds. Representative $N$-heterocyclic-containing drugs that serve as substrates for $\mathrm{AO}$ are famciclovir, methotrexate, 6-mercaptopurine, and cinchona alkaloids. ${ }^{1-6)}$ The oxidation mode by cytosolic AO is a nucleophilic attack at an electron-deficient carbon, which is different from an electrophilic attack at an electron-rich carbon by microsomal cytochrome $\mathrm{P} 450$, indicating that $\mathrm{AO}$ has complementary substrate specificities with P450 in the metabolism of xenobiotics. In addition, $\mathrm{AO}$ can catalyze in vitro reduction of a variety of functional groups including sulfoxides, $\mathrm{N}$-oxides, azo dyes, and $N$-hydroxycarbamoyl substituents in the presence of an appropriate electron donor. ${ }^{6}$ In fact, the atypical antipsychotic drug, ziprasidone, is mostly metabolized to its reductive ring-cleaved $S$-methyldihydroziprasidone by $\mathrm{AO}$ in human. ${ }^{7,8)}$

One of characteristics of $\mathrm{AO}$ is a marked species difference. For example, Sugihara et al. ${ }^{9)}$ investigated the enzyme activity in several animal species using a few model substrates with relatively simple chemical structures. Extremely high benzaldehyde oxidase activity was observed in monkey and low activity in guinea pig. 2-Hydroxypyrimidine was oxidized at the highest rate in rabbit and rat and at a low rate in mouse. Monkey showed the highest phthalazine oxidase activity among the animal species studied. $N^{1}$-methylnicotinamide oxidase activity was highest in rabbit and low in rat and mouse. Preliminary experiments demonstrated that human AO shows similar substrate specificity to that of monkey. Further, many medicines have been reported to show significant species differences in AO-catalyzed metabolism. They include an ocular hypotensive agent, brimonidine, ${ }^{10)}$ an antiviral drug, famciclovir and 6-deoxypenciclovir, ${ }^{11)}$ an antineoplastic drug, methotrexate, ${ }^{12,13)}$ an ultra-short acting hypnotic, zaleplon, ${ }^{14)}$ and an oral antitumor agent, zebularine. ${ }^{15)}$ Thus, it is now well established that the variations of AO activity may be dependent on not only animal species, but also on the chemical structures of the substrate. Roughly speaking, $\mathrm{AO}$ activity is high in monkey and human, moderate to low in rat and mouse, and deficient in dog.

We have been studying the metabolism of RS-8359, [( \pm 4-(4-cyanoanilino)-5,6-dihydro-7-hydroxy-7H-cyclopenta[d]-pyrimidine], which is a reversible and selective monoamine oxidase A (MAO-A) inhibitor ${ }^{16,17)}$ and has been developed as an anti-depressant. ${ }^{18,19)}$ The main metabolic pathway of the compound is the AO-catalyzed 2-oxidation on the pyrimidine ring of the molecule. Similar to many reports on $\mathrm{AO}$, we observed a remarkable species differences, ${ }^{20-22)} \mathrm{a}$ large strain difference in rat, ${ }^{23}$ and an individual difference in Donryu strain rat ${ }^{24)}$ in the 2-oxidation activity. Further, we reported that a minor $130 \mathrm{kDa}$ subunit in addition to a 150 $\mathrm{kDa}$ subunit was observed in the sodium dodecyl sulfatepolyacrylamide gel electrophoresis (SDS-PAGE)/Western blot analysis of monkey and human $\mathrm{AO}$ but not in rat $\mathrm{AO}{ }^{25}$ ) This minor subunit was suggested to lack the $\mathrm{N}$-terminus by nano-LC Q/TOF MS analysis of AO purified from monkey liver cytosol. Sugihara et al. ${ }^{9)}$ also demonstrated the existence of $130 \mathrm{kDa}$ subunit in monkey liver AO. The results might suggest the possible relationship between the much higher AO activity in human and monkey than in other animals and the existence of the $130 \mathrm{kDa}$ subunit. One of the best ways to verify this hypothesis would be to know whether 
AO protein including the $130 \mathrm{kDa}$ subunit maintains the catalytic activity. In the current study, we determined the N-terminal amino acid sequences of the $130 \mathrm{kDa}$ subunit, constructed an expression system of AO including the $130 \mathrm{kDa}$ subunit, and then characterized the properties of the expressed $\mathrm{AO}$ protein.

\section{MATERIALS AND METHODS}

Chemicals and Reagents The $(S)$-enantiomer of RS8359 and its 2-keto metabolite were supplied by Ube Kosan Co., Ltd. (Yamaguchi, Japan). Hydrocortisone, an internal standard of HPLC analysis, was purchased from Sigma Chemical Co. (St. Louis, MO, U.S.A.). Imidazole, sodium molybdic(VI) acid $\left(\mathrm{Na}_{2} \mathrm{MoO}_{4}\right)$, and isopropyl- $\beta$-D(-)-thiogalactopyranoside (IPTG) were obtained from Wako Pure Chemical Industries, Ltd. (Osaka, Japan). All other reagents were of reagent grade. Anti-His-tag antiserum was purchased from Medical \& Biological Laboratories Co., Ltd. (Nagoya, Japan).

Enzyme Activity Assay $(S)$-RS-8359 $(100 \mu \mathrm{M})$ was incubated at $37^{\circ} \mathrm{C}$ for $60 \mathrm{~min}$ in a reaction mixture $(0.25 \mathrm{ml})$ consisting of $100 \mathrm{~mm}$ phosphate buffer $(\mathrm{pH} 6.0), 1.0 \mathrm{~mm}$ $\mathrm{K}_{3} \mathrm{Fe}(\mathrm{CN})_{6}, 0.13 \mathrm{~mm}$ EDTA, and the expressed protein $(5-$ $20 \mu \mathrm{g} / \mathrm{ml}, 0.10 \mathrm{ml})$. The reaction was stopped by the addition of acetonitrile $(0.50 \mathrm{ml})$ containing $0.2 \mathrm{mg} / \mathrm{ml}$ of hydrocortisone as an internal standard. The mixture was then centrifuged at $10000 \boldsymbol{g}$ for $5 \mathrm{~min}$. Aliquots $(25 \mu \mathrm{l})$ of the supernatant were analyzed for quantification of the oxidation product by reversed-phase HPLC on a YMC ODS A-312 column (6.0 mm i.d. $\times 150 \mathrm{~mm}$, YMC Co., Ltd., Kyoto, Japan). The mobile phase was composed of acetonitrile $/ 0.5 \%$ ammonium acetate $(25: 75)$; the flow rate was $1.0 \mathrm{ml} / \mathrm{min}$. The HPLC instrument was a Shimadzu Model 6A High-Performance Liquid Chromatograph System (Shimadzu Seisakusho Co., Ltd., Kyoto, Japan). The peaks were monitored for absorbance at $315 \mathrm{~nm}$; the peak area was calculated on a Chromatopac CR4A (Shimadzu Seisakusho).

Preparation of Rabbit Anti-monkey AO Antisera Rabbit anti-monkey AO antisera used in this study were previously prepared by Hoshino et al. ${ }^{25)}$ Briefly, a necessary amount of monkey aldehyde oxidase was expressed in $E$. coli and purified by HisTrap HP column chromatography. The antibody was prepared by Shibayagi Co., Ltd. (Gunma, Japan). The purified enzyme $(1.0 \mathrm{mg}$ protein $/ \mathrm{ml})$ was emulsified with an equal volume of Freund's complete adjuvant (Sigma). Each of two rabbits was immunized with $1 \mathrm{ml}$ of immunogen by intradermal injections every 4 weeks. Four months after the first immunization, blood was obtained by cardiac puncture and antisera were prepared by a conventional method. Pooled antisera were stored at $-80^{\circ} \mathrm{C}$ until use for Western blot analysis.

Construction of Expression System for Monkey AO with His-tag at $\mathbf{N}$ - and $\mathbf{C}$-Terminus Monkey AO cDNA has already been subcloned and cryopreserved in pQE-30Xa vector (QIAGEN, Venlo, The Netherlands), which can add His-tag at the N-terminus. ${ }^{25)}$ Another expression system of monkey AO was newly constructed by using pQE-60 vector (QIAGEN), which can add His-tag at the C-terminus. For that, monkey AO cDNA was divided into three fragments of $1.7 \mathrm{kbp}$ and $0.5 \mathrm{kbp}$, which were synthesized by polymerase chain reaction $(\mathrm{PCR})$, and $2 \mathrm{kbp}$, which was prepared from the cryopreserved pQE-30Xa vector. The forward and reverse primers for the synthesis of the $1.7 \mathrm{kbp}$ DNA fragment were ggacactaccatggacaggg with an NcoI restriction site and ccaattgggtcttcaggatg, respectively. The reaction was conducted in a $50-\mu$ l solution containing $1 \times$ high fidelity PCR buffer, $200 \mu \mathrm{M}$ deoxynucleoside triphosphate (dNTP) mix, 1.25 U Platinum Taq DNA polymerase (Invitrogen, Carlsbad, CA, U.S.A.), $2 \mathrm{~mm} \mathrm{MgSO}_{4}, 0.5 \mu \mathrm{M}$ of each primer, and $2 \mu \mathrm{l}$ $(0.2 \mathrm{ng})$ of the template, which was prepared from the cryopreserved $\mathrm{pQE}-30 \mathrm{Xa}$. PCR amplifications were as follows: initial denaturation at $94^{\circ} \mathrm{C}$ for $2 \mathrm{~min}$, and 30 cycles of $94^{\circ} \mathrm{C}$ for $30 \mathrm{~s}, 60^{\circ} \mathrm{C}$ for $30 \mathrm{~s}, 68^{\circ} \mathrm{C}$ for $2 \mathrm{~min}$, and a final extension at $68^{\circ} \mathrm{C}$ for $3 \mathrm{~min}$. The $0.5 \mathrm{kbp}$ fragment was produced in almost the same manner by simply changing the forward and reverse primers to ggcccgaggttgaaatagactgc and gtttgcatttggatccgacgg with a Bam $\mathrm{HI}$ restriction site, respectively. The DNA sequences of the PCR products were determined by a CEQ 8000 Analysis System and a DTCS Quick Start Kit (Beckman-Coulter Inc., Fullerton, CA, U.S.A.) according to the method recommended by the manufacturer. Each $1.7 \mathrm{kbp}$ and $0.5 \mathrm{kbp}$ PCR product was treated with $N c o \mathrm{I} / P s t \mathrm{I}$ and Bam HI/PstI, respectively. All restriction enzymes were obtained from New England Biolabs, Inc. (Beverly, MA, U.S.A.). The two monkey AO DNA fragments were ligated with a pQE-60 vector that was pretreated with $N c o \mathrm{I} / B a m \mathrm{HI}$. The plasmids were digested with Pst $\mathrm{I}$, dephosphorylated, and then ligated with the $20 \mathrm{kbp}$ DNA fragment that was prepared by PstI-treatment of monkey AO full cDNA obtained from the preserved $\mathrm{pQE}-30 \mathrm{Xa}$ vector. The ligation was conducted using TaKaRa DNA Ligation Kit Ver. 2.1 (TaKaRa Bio Inc., Kyoto, Japan) according to the manufacturer's protocol. The insertion of monkey AO cDNA was confirmed by agarose gel electrophoresis of the Pst I/NcoI treatment product.

Construction of Expression System for Monkey AO Containing $130 \mathrm{kDa}$ Subunit PCR of long nucleotides corresponding to the $130 \mathrm{kDa}$ subunit is subject to result in PCR error. So, the pQE-30Xa plasmids in which complete monkey AO full cDNA had already been introduced were utilized for the construction of the objective expression system. The strategy to connect the two HindIII treated fragments is shown in Fig. 1. The forward primer, aggtaccccagaattcgagga, was designed in such a way that the initial amino acid becomes Pro and a restriction site fits to the frame of the pQE-30 Xa vector. The reverse primer was ccaattgggtcttcaggatg which was designed to contain PstI restriction site around the middle of full cDNA. The PCR products were digested with Acc65I and PstI, then introduced in pQE-30 Xa vector. After subcloning, the plasmids were treated with HindIII and the hydrolyzed fragments were connected with the fragments obtained by HindIII treatment of pQE-30 Xa vector with the complete monkey AO full cDNA. The resulting plasmids were transfected into E. coli M15 (pREP4, QIAGEN).

Cell Cultures Each AO cDNA plasmid prepared above was transfected into the expression E. coli M15 cells (pREP4, QIAGEN). The control sample was produced by transfection of the pQE-30 Xa vector or the pQE-60 vector. A single colony was cultured at $37^{\circ} \mathrm{C}$ overnight in $5 \mathrm{ml}$ of LB medium containing $50 \mu \mathrm{g} / \mathrm{ml}$ ampicillin and $25 \mu \mathrm{g} / \mathrm{ml}$ 


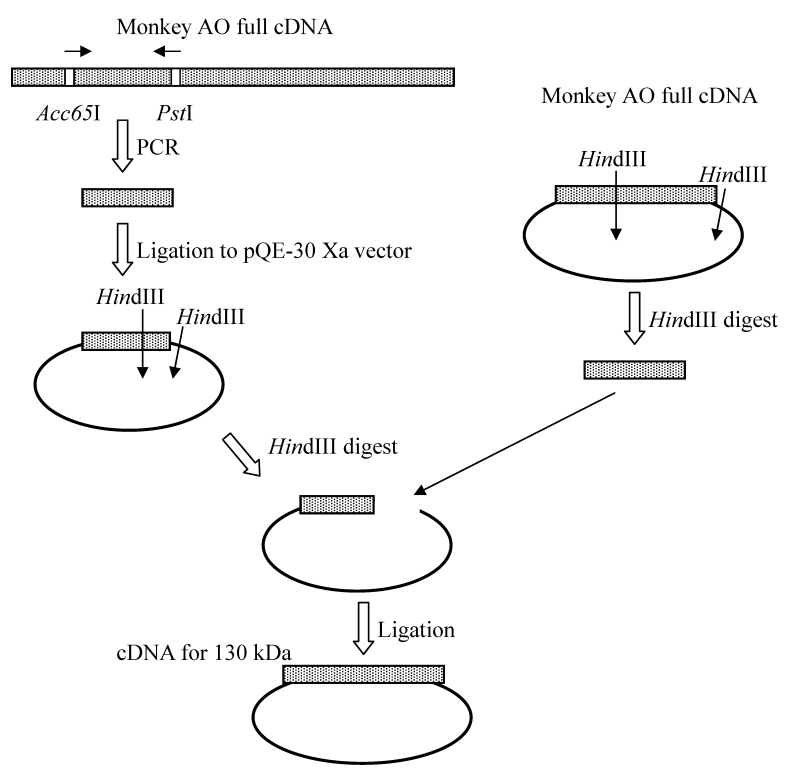

Fig. 1. Construction Strategy for AO Containing the $130 \mathrm{kDa}$ Subunit

kanamycin. To the overnight culture, $500 \mathrm{ml}$ of LB with 50 $\mu \mathrm{g} / \mathrm{ml}$ ampicillin and $25 \mu \mathrm{g} / \mathrm{ml}$ kanamycin were added and cultured at $37^{\circ} \mathrm{C}$ until absorbance at $600 \mathrm{~nm}$ reached $0.5-$ 0.6. Then, IPTG $(1 \mathrm{mM})$ was added to the mixture along with ATP $(1 \mathrm{~mm})$, riboflavin $(3 \mu \mathrm{M})$, and $\mathrm{Na}_{2} \mathrm{MoO}_{4}(50 \mu \mathrm{M})$ according to the methods previously reported by Huang et al. ${ }^{26}$ Growth of the culture was allowed to continue for $72 \mathrm{~h}$ at $22^{\circ} \mathrm{C}$. After collection by centrifugation at $7000 \mathrm{~g}$ for $10 \mathrm{~min}$ at $4{ }^{\circ} \mathrm{C}$, the cells were solubilized with QIAexpressionist (QIAGEN) according to the manufacturer's instructions. The soluble proteins were applied to a HisTrap HP Column (GE Healthcare Ltd. U.K., Buckinghamshire, England) fully preequilibrated with $10 \mathrm{~mm}$ phosphate buffer $(\mathrm{pH} 7.4)$ containing $20 \mathrm{~mm}$ imidazole and $0.5 \mathrm{M} \mathrm{NaCl}$. After being washed with $100 \mathrm{~mm}$ imidazole in the buffer, the objective enzyme was eluted with $250 \mathrm{~mm}$ imidazole in the buffer.

Sodium Dodecyl Sulfate Polyacrylamide Gel Electrophoresis (SDS-PAGE) The expressed enzymes were separated by SDS-PAGE, which was performed using PhastGel Gradient 4-15 in PhastGel SDS Buffer Strips (GE Healthcare). An automatic electrophoresis system, PhastSystem (GE Healthcare), was used. Protein bands were stained with Coomassie Brilliant Blue CBB R-350 (GE Healthcare). An HMW Calibration Kit and HMV Native Marker Kit (GE Healthcare) were used for molecular mass standards.

\section{RESULTS}

Construction of Expression System for Monkey AO with His-tag at the $\mathrm{N}$ - and $\mathrm{C}$-Terminus It seems to be a good way to characterize AO with His-tag at the $\mathrm{N}$ - and Cterminus by using anti-AO and anti-His-tag antisera in order to determine at which terminus the $150 \mathrm{kDa}$ subunit is cleaved. The expression system of monkey AO with His-tag at the $\mathrm{N}$-terminus has already been constructed. ${ }^{25}$ ) In this study, the expression system of another C-terminus His-tag $\mathrm{AO}$ subunit was newly constructed. The $150 \mathrm{kDa}$ and 130 $\mathrm{kDa}$ subunits were observed in both His-tag AO expression systems by anti-monkey $\mathrm{AO}$ antiserum, although the amount
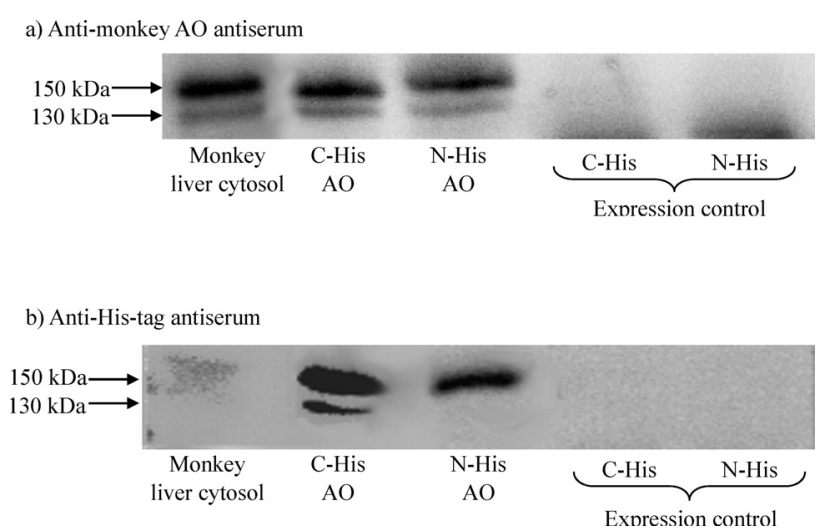

Fig. 2. Western Blot Analysis of Expressed AO Proteins with His-tag at $\mathrm{N}$ - and C-Terminus by (a) Anti-monkey AO Antiserum and (b) Anti-His-tag Antiserum

of $130 \mathrm{kDa}$ subunit was much smaller compared to the amount of $150 \mathrm{kDa}$ subunit (Fig. 2a). In contrast, when antiHis-tag antiserum was used, the $150 \mathrm{kDa}$ and $130 \mathrm{kDa}$ subunits were detected in the C-terminus His-tag $\mathrm{AO}$ expression system, but only the $150 \mathrm{kDa}$ subunit was seen in the N-terminus His-tag AO expression system (Fig. 2b).

N-Terminal Amino Acid Analysis of 130 kDa Subunit The AO protein containing the $130 \mathrm{kDa}$ subunit was expressed using the pQE-30 Xa vector, which can add His-tag at the N-terminus, and purified with HisTrap HP column chromatography. The proteins on the gel after SDS-PAGE were transferred to a PVDF membrane. The CBB-stained $130 \mathrm{kDa}$ subunit was cut off and its N-terminal amino acids were analyzed by Edman degradation. The N-terminal amino acid of the $130 \mathrm{kDa}$ subunit was 189Pro of $150 \mathrm{kDa}$ subunit (Fig. 3), which is located in the linkage portion between the $2 \mathrm{Fe}-2 \mathrm{~S}$ cluster and FAD domains (Fig. 4).

Construction of Expression System for Monkey AO Containing $130 \mathrm{kDa}$ Subunit The construction strategy for cDNA expressing the $130 \mathrm{kDa}$ subunit of monkey $\mathrm{AO}$ is illustrated in Fig. 1. The protein expressed in E. coli M15 cells was purified by HisTrap HP column chromatography. SDS-PAGE/Western blot analysis of the purified protein using anti-monkey $\mathrm{AO}$ antiserum revealed one band with a molecular mass of $130 \mathrm{kDa}$ (Fig. 5), which is the same migrating position as the minor $130 \mathrm{kDa}$ subunit of monkey liver cytosol and the expressed $\mathrm{AO}$ proteins.

Activity of Monkey AO Containing $130 \mathrm{kDa}$ Subunit The AO-catalyzed 2-oxidation activity of $(S)$-RS-8359 was measured for the expressed AO containing the $130 \mathrm{kDa}$ subunit. Although the expressed protein of monkey AO full cDNA used as a positive control showed high AO activity, AO containing the $130 \mathrm{kDa}$ subunit had no activity at all (Fig. 6).

\section{DISCUSSION}

$\mathrm{AO}$ is a homodimer with a subunit molecular mass of about $150 \mathrm{kDa}$. Each subunit consists of about $20 \mathrm{kDa}$ of $2 \mathrm{Fe}-2 \mathrm{~S}$ cluster domain, about $40 \mathrm{kDa}$ of FAD containing domain and about $85 \mathrm{kDa}$ molybdenum cofactor containing domain. Previously, we demonstrated that a minor $130 \mathrm{kDa}$ subunit as well as a major $150 \mathrm{kDa}$ subunit was detected in SDSPAGE/Western blot analysis of the expressed proteins of 


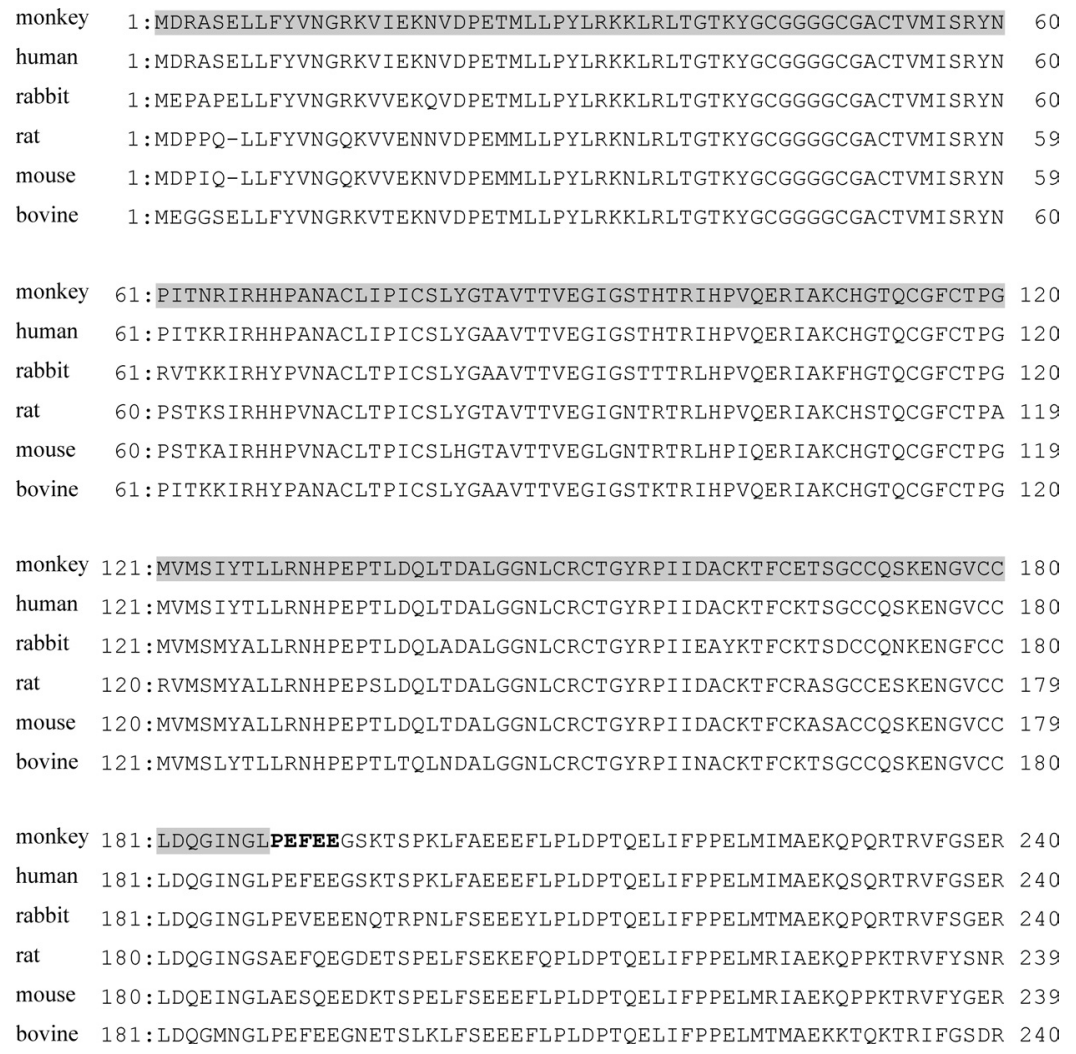

Fig. 3. Partial Amino Acid Sequences of AO from Several Animal Species

The bold peptides are the $\mathrm{N}$-terminal amino acid sequences of the $130 \mathrm{kDa}$ component of monkey AO as analyzed by Edman degradation. The gray-shadowed amino acids indicate the sequences lost by cleavage.

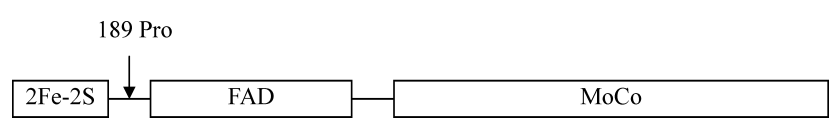

Fig. 4. Structural Model of AO and the Cleavage Position Leading to Formation of the $130 \mathrm{kDa}$ Component

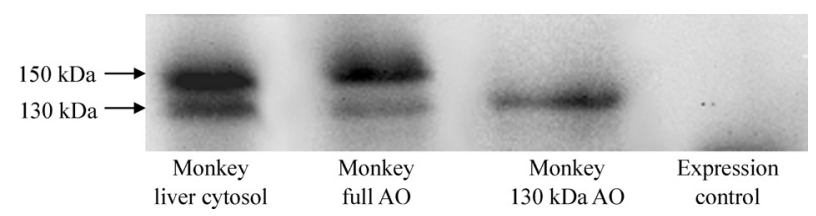

Fig. 5. Western Blot Analysis of Expressed AO Protein Containing the $130 \mathrm{kDa}$ Subunit

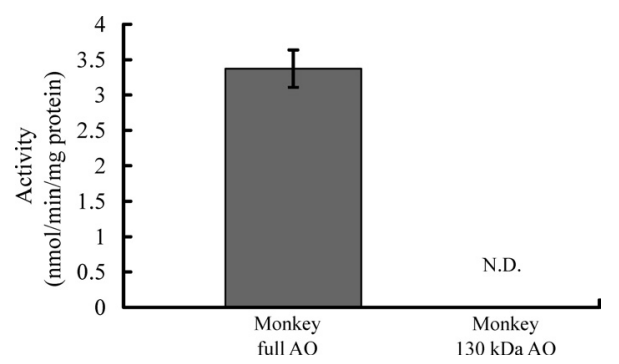

Fig. 6. AO-Catalyzed 2-Oxidation Activity of ( $S$ )-RS-8359 by Expressed AO Protein Containing the $130 \mathrm{kDa}$ Subunit

monkey AO full cDNA. ${ }^{25)}$ Almost the same electrophoretic behavior was observed in the Western blot analysis of AO purified from monkey liver cytosol. In rat, however, such 130 $\mathrm{kDa}$ subunit was observed in neither the in vitro expression protein nor in the in vivo liver samples. The addition of protease inhibitors during enzyme purification did not affect formation of the $130 \mathrm{kDa}$ subunit. The results suggest that the $130 \mathrm{kDa}$ subunit seems to have already been formed by a proteolytic process after being biosynthesized within the ribosomes in the liver cells of monkey and human, and also in the E. coli expression system of monkey AO, but not in rat $\mathrm{AO}$.

The $130 \mathrm{kDa}$ subunit was assumed to be produced by cleavage at the N-terminal side by nano-LC Q/TOF MS analysis of $\mathrm{AO}$ purified from monkey liver cytosol. ${ }^{25)}$ To confirm this assumption, two types of $\mathrm{AO}$ protein with His-tag at the $\mathrm{N}$ - and $\mathrm{C}$-terminus were expressed in $E$. coli by using the pQE-30 and pQE-60 vectors, respectively, and purified with HisTrap HP column chromatography. The N-terminus Histag AO showed both the major $150 \mathrm{kDa}$ and the minor 130 $\mathrm{kDa}$ subunits against anti-AO antiserum, but only the 150 $\mathrm{kDa}$ subunit against anti-His-tag antiserum. The C-terminus His-tag AO displayed both the $150 \mathrm{kDa}$ and the $130 \mathrm{kDa}$ subunits against both anti-AO and anti-His-tag antisera. There might be two possible explanations for the production of the $130 \mathrm{kDa}$ subunit. The first possibility is illustrated in Fig. 7, in which $\mathrm{AO}$ partially lacks a $20 \mathrm{kDa}$ fragment and exists as a heterodimer of $150 \mathrm{kDa} / 130 \mathrm{kDa}$. The heterodimer purified with HisTrap HP column chromatography yielded the 150 $\mathrm{kDa}$ and $130 \mathrm{kDa}$ subunits by SDS treatment. The second possibility is given in Fig. 8. As is shown, each of the $2 \mathrm{Fe}-2 \mathrm{~S}$ and FAD domains is connected with a MoCo domain by 


$$
\begin{aligned}
& 150 \mathrm{kDa} / 130 \mathrm{kDa} \quad 130 \mathrm{kDa} \text { homodimer } \\
& \text { heterodimer }
\end{aligned}
$$
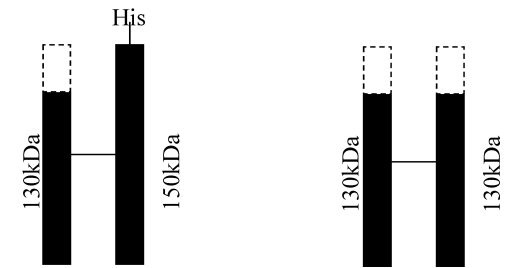

Fig. 7. Formation Hypothesis of the $130 \mathrm{kDa}$ Component from the 150 $\mathrm{kDa} / 130 \mathrm{kDa}$ Heterodimer or the $130 \mathrm{kDa} / 130 \mathrm{kDa}$ Homodimer

The expressed proteins were purified by His-Trap HP column chromatography and analyzed by SDS-PAGE/Western blot. The N-terminus His-tag AO showed both the major $150 \mathrm{kDa}$ and the minor $130 \mathrm{kDa}$ proteins against anti-AO antiserum, but only the $150 \mathrm{kDa}$ protein against anti-His-tag antiserum. The C-terminus His-tag AO displayed both the $150 \mathrm{kDa}$ and the $130 \mathrm{kDa}$ proteins against both anti-AO and anti-His-tag antisera.

a) $150 \mathrm{kDa} \mathrm{AO}$ protein

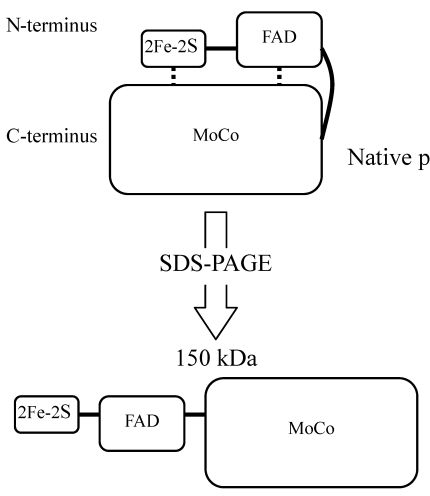

b) $130+20 \mathrm{kDa} \mathrm{AO}$ protein (apparent $150 \mathrm{kDa}$ )

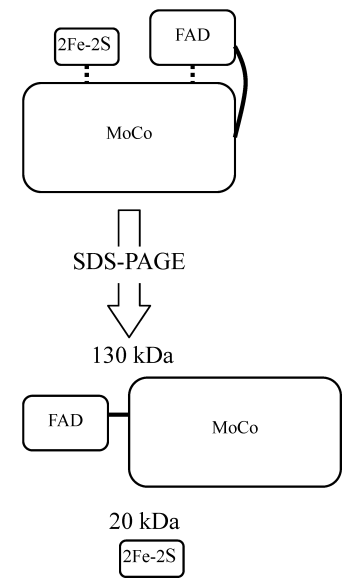

Fig. 8. Formation Hypothesis of the $130 \mathrm{kDa}$ Component from the 150 $\mathrm{kDa}$ Component through Bond Cleavage between the $2 \mathrm{Fe}-2 \mathrm{~S}$ and FAD Domains in Monkey AO

The results of SDS-PAGE/Western blot analysis were the same as those described in the legend of Fig. 7.

disulfide bonding, but the linkage between the $2 \mathrm{Fe}-2 \mathrm{~S}$ and FAD domains, which is maintained in the normal $150 \mathrm{kDa}$ subunit, is absent. Therefore, the subunit exists as a $130+20$ $\mathrm{kDa}$ protein (apparent $150 \mathrm{kDa}$ ). A large amount of the normal dimer along with a small amount of the unusual dimer consisting of the apparent $150 \mathrm{kDa}$ subunit was adsorbed and purified using HisTrap HP column chromatography. SDStreatment yielded the $150 \mathrm{kDa}$ subunit from the former dimer and the $130 \mathrm{kDa}$ subunit from the latter dimer. Although other explanations might exist, these two seem to clearly describe the results obtained by using the two kinds of His-tag proteins and the two kinds of antisera. We do not have any experimental evidence to conclude which is correct, but it is obvious that the $130 \mathrm{kDa}$ subunit is produced by cleavage at the N-terminus of the $150 \mathrm{kDa}$ subunit.

Determination of the precise cleavage point of the $150 \mathrm{kDa}$ subunit is necessary to clarify the function of the $130 \mathrm{kDa}$ subunit using the expression technique. Edman degradation analysis of the expressed minor $130 \mathrm{kDa}$ subunit revealed that the cleavage point is located between 188Lue and 189Pro of the $150 \mathrm{kDa}$ subunit. These amino acid sequences were present in $\mathrm{AO}$ of human, ${ }^{27)}$ bovine $^{28)}$ and rabbit $^{26)}$ as well as monkey, ${ }^{25}$ but not in that of rat $(188 \mathrm{Ser} / 189 \mathrm{Ala})^{29)}$ and mouse (188Leu/189Ala) ${ }^{30)}$ as shown in Fig. 3. The minor $130 \mathrm{kDa}$ subunit is detected in $\mathrm{AO}$ of humans (data not shown), but not in $\mathrm{AO}$ of rats and mice. Calzi et al. ${ }^{28)}$ reported a single $150 \mathrm{kDa}$ protein band on SDS-PAGE of purified bovine $\mathrm{AO}$, however the minor $130 \mathrm{kDa}$ protein could be observed although a small amount. According to Huang et al. ${ }^{26)}$ the AO purified from rabbit liver cytosol gave a single electrophoretical protein band on SDS-PAGE. The amino acid sequences of guinea pig $\mathrm{AO}$ have not been reported and the existence of $130 \mathrm{kDa}$ minor subunit has been controversial. ${ }^{9,31)}$ Thus, it seemed likely that the existence or absence of the $130 \mathrm{kDa}$ minor subunit correlates to the amino acid sequences of 188Lue and 189Pro as seen in human, monkey, rat, mouse, and possibly bovine. However, some factors other than the amino acid sequences might be required for the formation of the $130 \mathrm{kDa}$ subunit in rabbit.

The amino acid sequences of 188Leu and 189Pro are included in the linkage between the $2 \mathrm{Fe}-2 \mathrm{~S}$ and FAD domains. ${ }^{29)}$ The cleavage results in the loss of the $2 \mathrm{Fe}-2 \mathrm{~S}$ cluster domain essentially required for $\mathrm{AO}$ activity. In fact, the expressed AO protein containing the $130 \mathrm{kDa}$ subunit showed no catalytic activity at all. This means that the existence of $130 \mathrm{kDa}$ subunit is obviously not associated with the high AO activity in monkey and human. Previously, a biphasic pattern was shown in Eadie-Hofstee plots for the AO-catalyzed 2-oxidation of $(S)$-RS-8359 that suggested the existence of two AO isoforms or two active sites in a single enzyme. $^{25)}$ The results obtained in this study are likely to rule out the possibility of the existence of two isoforms because the AO protein containing the $130 \mathrm{kDa}$ subunit has no activity. The properties of protease hydrolyzing the peptide bond between 188Leu and 189Pro are as yet unknown, and that will be a future problem.

In conclusion, the $130 \mathrm{kDa} \mathrm{AO}$ subunit was shown to be produced by cleavage between 188Leu and 189Pro of the $150 \mathrm{kDa}$ subunit. The existence of the amino acid sequences might be one major reason for the species difference in the formation of the minor $130 \mathrm{kDa}$ subunit. However, the existence of the $130 \mathrm{kDa}$ subunit is not associated with the species differences in $\mathrm{AO}$ activity, because the cleavage results in the loss of the $2 \mathrm{Fe}-2 \mathrm{~S}$ cluster domain essential for exertion of $\mathrm{AO}$ activity.

\section{REFERENCES}

1) Beedham C., Drug Metab. Rev., 16, 119-156 (1985).

2) Beedham C., Prog. Med. Chem., 24, 85-121(1987).

3) Beedham C., Pharm. World Sci., 19, 255-263 (1997).

4) Beedham C., "Metabolism of Xenobiotics," ed. by Gorrod J. W., Oeschlager H., Caldwell J., Taylor \& Francis, London, 1998, pp. 5158.

5) Beedham C., "Enzyme Systems That Metabolise Drug and Other Xenobiotics," ed. by Ioannides C., John Wiley, London, 2002, pp. $147-187$.

6) Kitamura S., Sugihara K., Ohta S., Drug Metab. Pharmacokinet., 21, $83-98$ (2006)

7) Prakash C., Kamel A., Gummerus J., Wilner K., Drug Metab. Dispos., 25, 863-875 (1997).

8) Beedham C., Miceli J. J., Obach S., J. Clin. Psychopharmacol., 23, 229-232 (2003).

9) Sugihara K., Katsuma Y., Kitamura S., Ohta S., Fujitani M., Shintani H., Comp. Biochem. Physiol., Part C, 126, 53-60 (2000). 
10) Acheampong A. A., Chien D-S., Lam S., Vekich S., Breau A., Usansky J., Harcourt D., Munk S. A., Nguyen H., Garst M., Tang-Liu D., Xenobiotica, 26, 1035-1055 (1996).

11) Rashidi M. R., Smith J. A., Clarke S. E., Beedham C., Drug Metab. Dispos., 25, 805-813 (1997).

12) Kitamura S., Sugihara K., Nakatani K., Ohta S., O'Hara T., Nimomiya S., Green C. E., Tyson C. A ., UBMB Life, 48, 607-611 (1999).

13) Jordan C. G. M., Rashidi M. R., Laljee H., Clarke S. E., Brown J. E. Beedham C., J. Pharm. Pharmacol., 51, 411-418 (1999).

14) Kawashima K., Hosoi K., Naruke T., Shiba T., Kitamura M., Watabe T., Drug Metab. Dispos., 27, 422 - 428 (1999).

15) Klecker R. W., Cysyk R. L., Collins J. M., Bioorg. Med. Chem., 14, $62-66$ (2006).

16) Yokoyama T., Karube T., Iwata N., J. Pharm. Pharmacol., 41, 32-36 (1989).

17) Miura H., Naoi M., Nakahara D., Ohta T., Nagatsu T., J. Neural. Transm., 94, 175-187 (1993).

18) Plenker A., Puchler K., Volz H. P., Int. Clin. Psychopharm., 12, S25S29 (1997).

19) Puchler K., Schaffler K., Plenker A., Int. Clin. Psychopharm., 12, S17-S23 (1997).

20) Takasaki W., Yamamura M., Nozaki A., Nitanai T., Sasahara K., Itoh K., Tanaka Y., Chirality, 17, 135-141 (2005).

21) Itoh K., Yamamura M., Muramatsu S., Hoshino K., Masubuchi A., Sasaki T., Tanaka Y., Xenobiotica, 35, 561—573 (2005).
22) Itoh K., Yamamura M., Takasaki W., Sasaki T., Masubuchi A., Tanaka Y., Biopharm. Drug Dispos., 27, 133-139 (2006).

23) Sasaki T., Masubuchi A., Yamamura M., Watanabe N., Hiratsuka M., Mizugaki M., Itoh K., Tanaka Y., Biopharm. Drug Dispos., 27, 247255 (2006).

24) Itoh K., Masubuchi A., Sasaki T., Adachi M., Watanabe N., Nagata K., Yamazoe Y., Hiratsuka M., Mizugaki M., Tanaka Y., Drug Metab. Dispos., 35, 734-739 (2007).

25) Hoshino K., Itoh K., Masubuchi A., Adachi M., Watanabe N., Kosaka T., Tanaka Y., Biol. Pharm. Bull., 30, 1191-1198 (2007).

26) Huang D. Y., Furukawa A., Ichikawa Y., Arch. Biochem. Biophys., 364, 264-272 (1999).

27) Wright R. M., Vaitaitis G. M., Wilson C. M., Repine T. B., Terada L. S., Repine J. E., Proc. Natl. Acad. Sci. U.S.A., 90, 10690-10694 (1993).

28) Calzi M. L., Raviolo C., Ghibaudi E., deGioia L., Salmona M., Cazzaniga G., Kurosaki M., Terao M., Garattini E., J. Biol. Chem., 270, 31037-31045 (1995).

29) Wright R. M., Clayton D. A., Riley M. G., McManaman J. L., Repine J. E., J. Biol. Chem., 274, 3878-3886 (1999).

30) Kurosaki M., Demontis S., Barzago M. M., Garattini E., Terao M., Biochem. J., 341, 71-80 (1999).

31) Yoshihara S., Tatsumi K., Arch. Biochem. Biophys., 242, 213-224 (1985). 